\title{
Psychological Science
}

Kin Affiliation Across the Ovulatory Cycle : Females Avoid Fathers When Fertile Debra Lieberman, Elizabeth G. Pillsworth and Martie G. Haselton

Psychological Science 2011 22: 13 originally published online 24 November 2010

DOI: $10.1177 / 0956797610390385$

The online version of this article can be found at:

http://pss.sagepub.com/content/22/1/13

Published by:

(S)SAGE

http://www.sagepublications.com

On behalf of:

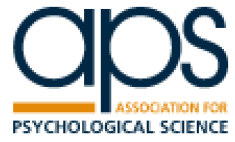

Association for Psychological Science

Additional services and information for Psychological Science can be found at:

Email Alerts: http://pss.sagepub.com/cgi/alerts

Subscriptions: http://pss.sagepub.com/subscriptions

Reprints: http://www.sagepub.com/journalsReprints.nav

Permissions: http://www.sagepub.com/journalsPermissions.nav 


\title{
Kin Affiliation Across the Ovulatory Cycle: Females Avoid Fathers When Fertile
}

Psychological Science 22(I) 13-18

(c) The Author(s) 2011

Reprints and permission:

sagepub.com/journalsPermissions.nav DOI: $10.1177 / 0956797610390385$

http://pss.sagepub.com

@SAGE

\author{
Debra Lieberman', Elizabeth G. Pillsworth ${ }^{2}$, and Martie G. Haselton ${ }^{3}$ \\ 'Department of Psychology, University of Miami; ${ }^{2}$ Department of Anthropology, California State University, Fullerton; and \\ ${ }^{3}$ Departments of Communication Studies and Psychology, University of California, Los Angeles
}

\begin{abstract}
A commonplace observation in humans is that close genetic relatives tend to avoid one another as sexual partners. Despite the growing psychological research on how antierotic attitudes develop toward relatives, few studies have focused on actual behavior. One prediction, stemming from parental investment theory, is that women should be more vigilant of reproductioncompromising behaviors, such as inbreeding, during times of peak fertility than during times of low fertility. Indeed, females of other species avoid interactions with male kin when fertile-but the corollary behavior in humans has yet to be explored. Here we fill this gap. Using duration and frequency of cell-phone calls, an objective behavioral measure that reflects motivations to interact socially, we show that women selectively avoid interactions with their fathers during peak fertility. Avoidance specifically targeted fathers, which rules out alternative explanations. These data suggest that psychological mechanisms underlying mating psychology regulate sexual avoidance behaviors, and in women they fluctuate according to fertility status.
\end{abstract}

\section{Keywords}

inbreeding avoidance, menstrual cycle, fertility, kin, communication

Received 4/I/I0; Revision accepted 8//2/10

Until recently, scientists assumed that estrus, a phase of fertile sexuality in females, had been lost in humans (Gangestad \& Thornhill, 2008; Haselton \& Gildersleeve, in press). However, a growing body of literature documents that over the course of the menstrual cycle, women display shifts in mating preferences toward partners with characteristics conferring reproductive benefits. During periods of high fertility, women prefer more masculine faces (Johnston, Hagel, Franklin, Fink, \& Grammer, 2001; Penton-Voak et al., 1999), more masculine voices (Puts, 2005), the scent of more symmetrical men (Gangestad \& Thornhill, 1998), and men displaying more dominant and intrasexually competitive behaviors (Gangestad, Simpson, Cousins, Garver-Apgar, \& Christensen, 2004).

In addition to producing shifts in preferences for reproductionenhancing attributes, natural selection should have engineered mate-choice mechanisms to avoid partners with reproductioncompromising traits, especially when conception risk is high. One trait to avoid is genetic relatedness. Offspring of related individuals run the risk of reduced health and survivability because of the increased probability of expressing deleterious recessive mutations and complications associated with disease-causing organisms (Bittles \& Neel, 1994; Ilmonen et al., 2008; Tooby, 1982). This is why evolution is thought to have shaped inbreeding avoidance mechanisms in many species, including humans (Clutton-Brock, 1989; Lieberman, Tooby, $\&$ Cosmides, 2007).

The functional design of inbreeding avoidance mechanisms should reflect the costs of different mating decisions. The genetic relatedness of potential mates and the magnitude of investment in offspring are two dimensions that contribute to these costs (Haig, 1999). Another dimension is conception risk. In many species, females are fertile for a short window of time. Given their generally high levels of parental investment (Trivers, 1972), females should show heightened sensitivity toward potentially costly sexual behaviors, such as inbreeding, especially during periods of peak fertility. In support of this prediction, studies have shown that nonhuman females from a variety of species avoid male kin during estrus (cats: Ishida, Yahara, Kasuya, \& Yamane, 2001; horses: Monard, Duncan, \& Boy, 1996; voles: Boyd \& Blaustein, 1985; mice: Winn \& Vestal, 1986). In humans, women report greater disgust toward biologically costly sexual behaviors (e.g., incest and bestiality) during periods of high fertility (Fessler \& Navarrete,

\section{Corresponding Author:}

Martie G. Haselton, Departments of Communication Studies and Psychology, 2303 Rolfe Hall, Los Angeles, CA 90095-1538

E-mail: haselton@ucla.edu 
2003), but what is not known is whether these attitudes translate into manifest behavior. Do women, like females of other species, show evidence of behavioral avoidance of male kin during peak fertility?

Unlike nonhuman animals, humans cannot be enclosed in a limited space and continuously videotaped to measure the frequency and duration of their interactions. Instead, we measured social interactions via one medium thought to reflect, in part, underlying motivations to associate: the cell phone. We predicted that, through the noise of individual habits and dayto-day changes in circumstances, we would observe evidence that women avoid male kin during periods of high fertility. We selected fathers as the male kin of interest for two reasons: First, most women in our sample were in touch with their fathers, and second, most women in our sample were in touch with their mothers, which allowed us to test the selectivity of avoidance and rule out alternative hypotheses.

Using the number and duration of incoming and outgoing calls to mothers and fathers as dependent measures, we tested four predictions. First, we predicted that there would be an interactive effect of fertility status (high vs. low fertility) and kin type (father vs. mother) on the number and duration of outgoing calls. Specifically, we predicted that during periods of high fertility, as compared with periods of low fertility, women would interact less with their fathers than with their mothers, as evidenced by fewer outgoing calls and calls of shorter duration. Second, we expected that any observed avoidance behavior during peak fertility would selectively target fathers and not mothers. Third, we did not expect there to be any effect of fertility status, nor any interactive effect of fertility status and kin type, on the number of calls initiated by parents (i.e., incoming calls). However, our last prediction was that we expected to see an effect of fertility status on the duration of incoming calls, with calls from fathers being shorter when daughters were fertile than when they were not. With these predictions in mind, we designed the following study.

\section{Method}

\section{Participants}

Fifty-one normally ovulating women (mean age $=19.0$ years) were recruited from the University of California, Los Angeles (UCLA). Participants received either payment or class credit for their participation. This study was reviewed and approved by the UCLA Institutional Review Board.

\section{Materials and procedure}

Participants provided their most recent itemized cell-phone bill. For all incoming and outgoing calls, participants identified by initials the person to which each phone number belonged. All other identifying information was then removed from the phone bill. On a separate form, each participant reported each contact's sex, age, and relationship to the participant, as well as the degree of closeness the participant felt toward the contact (on a scale from 1, not at all close, to 5, extremely close). Three participants were omitted from the study because they provided incomplete information. Analyses focused on the data from the remaining 48 participants, of whom 31 listed separate calls with their mother and father during the billing period, 14 listed calls only with their mother, and 3 listed calls only with their father.

Participants reported their menstrual onset dates surrounding the time period captured in their phone bill (phone bills covered 29-31 days). This information included menstrual onset dates for the 2 months prior to the commencement of the study and up to 3 subsequent menstrual onset dates. (Participants were involved in a separate longitudinal study that enabled researchers to maintain contact with participants and to collect these data.) We identified each participant's first menstrual onset date following the last day of her phone bill. Following the method used in earlier studies (e.g., Gangestad \& Thornhill, 1998; Haselton \& Gangestad, 2006), we counted backward from this date to identify high-fertility days (15-19 days prior to menstrual onset) and low-fertility days (4-12 days prior to menstrual onset) within the billing period (Wilcox, Dunson, Weinberg, Trussell, \& Baird, 2001). The backwardcounting method is preferred over forward counting because of greater variation in the length of the follicular phase compared with the luteal phase (Baird et al., 1995; Fehring, Schneider, \& Raviele, 2006). Because the billing cycles were independent of participants' menstrual cycles, there was variation in the total number of high- and low-fertility days captured across participants' phone bills (average number of high-fertility days $=$ 5.23; average number of low-fertility days $=9.54$ ). Statistical analyses described in the next section controlled for this variation. In all, our data captured a total of 921 phone calls (total of 4,186 min) made to and from participants' fathers and mothers during low- and high- fertility days.

\section{Data analyses}

Multilevel analyses treated each day and each dyad (fatherdaughter or mother-daughter) as a separate observation. This allowed us to compare fertility effects on father-daughter dyads and mother-daughter dyads even though not all participants reported communication with both their father and their mother. That is, analyses were not strictly within subjects; rather, they compared patterns observed among father-daughter dyads with patterns observed among mother-daughter dyads. This method also allowed us to use data from all qualifying high- and low-fertility days within each participant's phonebill cycle while controlling for the variation in the number of high- and low-fertility days observed and for the total number of days observed across participants. We used a multilevel mixed-effects Poisson regression model to test our predictions, as this model controlled for the interdependence of multiple observations (multiple days of calls) within each dyad and the interdependence of multiple dyads (father-daughter 
and mother-daughter) for each participant. This analysis was also robust to nonnormally distributed count variables, such as the number of calls made in a day. Degree of closeness to the parent was a covariate in all analyses. Analyses were conducted in Stata 10 (Rabe-Hesketh \& Skrondal, 2008).

\section{Results}

As shown in Figure 1, we found the predicted interaction between fertility status and kin type, for both the average number $(z=5.34, p<.001$; Fig. 1a) and the duration $(z=9.35, p<$ .001 ; Fig. 1b) of calls participants made per day (i.e., outgoing calls). During periods of high fertility, women called their fathers significantly less often than their mothers $(z=-4.29$, $p<.001)$ and talked for fewer minutes with their fathers than with their mothers $(z=-7.66, p<.001)$. This pattern was not found during periods of low fertility. This interaction was also significant when we used average minutes per call as a dependent measure $(z=2.56, p=.011)$. These effects held after controlling for the closeness of the relationship and the interaction between closeness and fertility status. It is important to note that this finding is not a result of fertile women making fewer calls to parents in general, as women did not show a reduction in calling behavior to their mothers during high-fertility periods. Thus, behavioral avoidance during peak fertility appears to selectively target fathers.

What about the calling behavior of parents? Inbreeding avoidance mechanisms in daughters should not affect the number of calls received from parents. Indeed, there was no main effect of fertility on the number of calls participants received from parents in general, nor any difference between the number of calls they received during high fertility versus low fertility from either their mothers or their fathers.

Whereas daughters do not have control over how often their parents might call, they do have a say in the duration of these calls. If women have psychological adaptations to avoid their fathers during periods of high fertility, then this should be manifest in the amount of time women remain on the phone when their fathers call. Indeed, our data show that women spent significantly less total time on calls from their fathers during high-fertility days $(M=0.74 \mathrm{~min}$ per day, $S E=0.30)$ than during low-fertility days $(M=1.16 \mathrm{~min}$ per day, $S E=0.42 ; z=-4.34, p<.001)$. Women also spent significantly fewer minutes per call on calls received from their fathers on high-fertility days $(M=4.69, S E=1.33)$ than on low-fertility days $(M=5.08, S E=0.93 ; z=-3.15, p=.002)$. Although our data also show that women spent less time on calls received from their mothers on high-fertility days

b

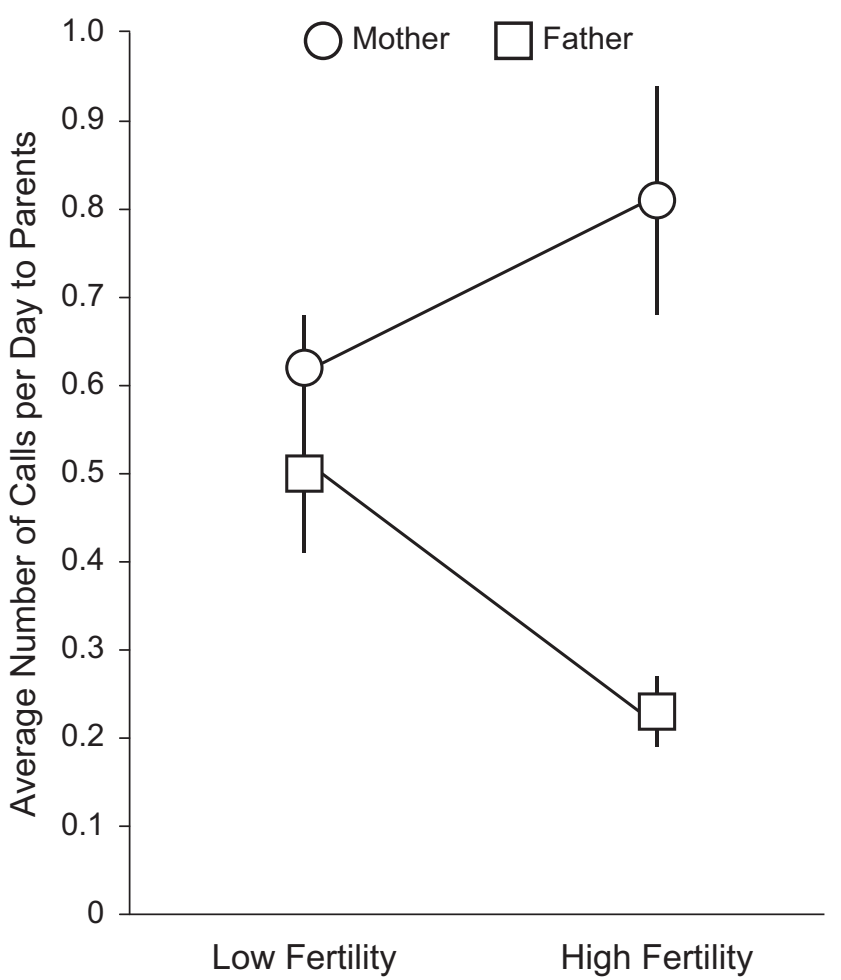

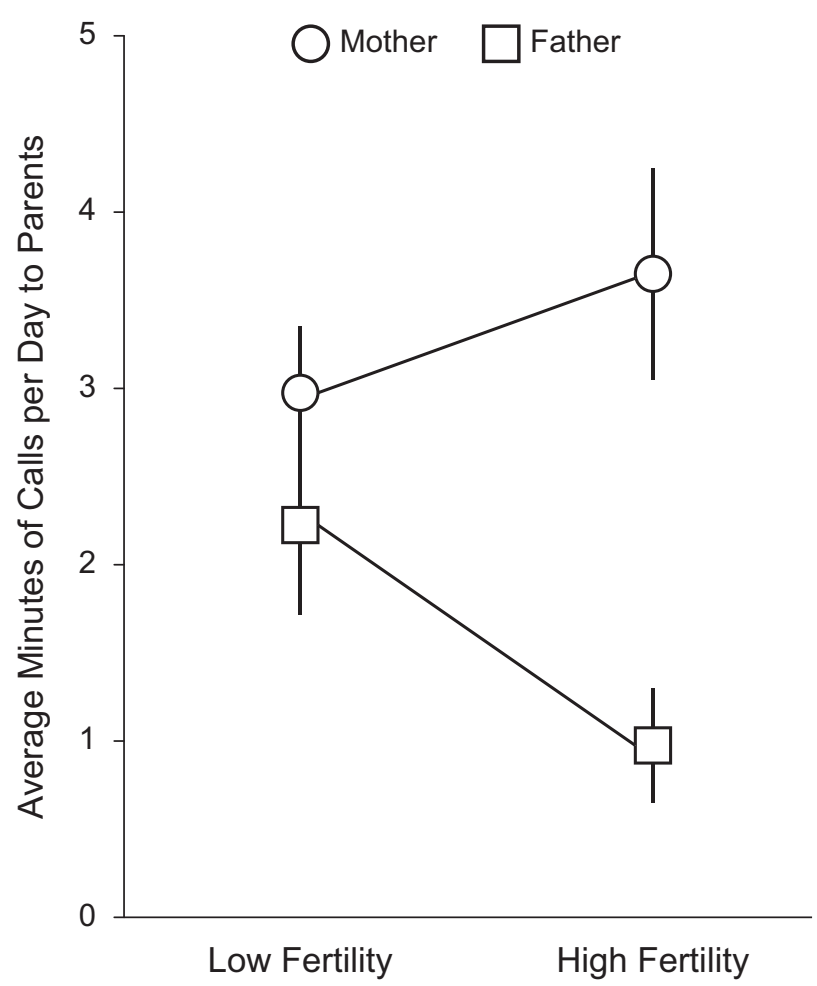

Fig. I. Effect of fertility status and kin type on participants' outgoing calls to their mothers and fathers. The graphs present (a) the average number of calls per day and (b) the average total duration of calls per day as a function of fertility (high vs. low) and kin type (father vs. mother). Error bars represent standard errors. 
compared with low-fertility days $(z=-2.91, p=.004)$, the effect of fertility was more pronounced for calls from fathers $(z=1.71, p=.087)$. Furthermore, in contrast to the pattern observed for calls from fathers, there was no effect of fertility status on the number of minutes per call for the calls received from mothers.

\section{Discussion}

These data provide the first behavioral evidence that women selectively avoid male kin during periods of peak fertility. The reduction in participants' mean number and duration of calls to their fathers during periods of high fertility was coupled with a decrease in variation for both measures - number of calls: $F(1,464)=4.83, p=.028$; call duration: $F(1,464)=2.95, p=$ .086 (Levene-Brown-Forsythe test for equality of variances). This decrease in variance was not observed for mothers $(p s=.12$ and .32 , respectively), which points to the operation of a finely tuned system for reducing affiliation. These data complement prior evidence showing the selective enhancement of sexual disgust during peak fertility (Fessler \& Navarrete, 2003) and suggest that mechanisms that reduce the occurrence of reproductioncompromising sexual behaviors - such as inbreeding - regulate actual behavior as well as self-reported attitudes.

Our data raise a number of questions and call attention to larger conceptual issues relating to kinship and sexual psychology. One question raised by these data is whether the pattern of social interactions between daughters and their fathers is the functional output of inbreeding avoidance mechanisms or a by-product of other psychological mechanisms involved in mating. For instance, as Figure 1 suggests, women might not be avoiding their fathers so much as preferring their mothers during periods of peak fertility. To the extent that females increase behaviors and preferences associated with selecting a high-quality mate during peak fertility, daughters might call their mothers more often during peak fertility to discuss relationshiprelevant events. As a by-product, this would leave less time for women to talk to their fathers. Two strands of evidence suggest that this simple by-product explanation cannot account for the observed reduction in women's affiliation with their fathers during periods of high fertility.

First, if more time on the phone with mothers during periods of peak fertility leaves less time to talk to fathers, there should be a significant negative correlation between the number of calls to mothers and the number of calls to fathers, as well as a significant negative correlation between the duration of calls to mothers and the duration of calls to fathers. However, we did not observe such negative correlations $(p s=.49$ and .38 , respectively). Thus, calling patterns to fathers cannot be explained by a zero-sum relationship between talk time with mothers versus talk time with fathers.

Second, only women who reported being close to their mother increased the number $(z=2.55, p=.011)$ and duration $(z=7.39, p<.001)$ of calls to their mother during periods of high fertility. However, closeness did not explain the reduction in calling behavior to fathers: Women reduced their calling behavior to fathers on high-fertility days regardless of how close they felt to their fathers. Thus, the variable that accounts for the increase in calling behavior to mothers does not account for the decrease in calling behavior to fathers, a pattern that militates against a simple by-product explanation.

We suspect our data reveal the operation of two different systems: one motivating females to avoid their fathers during periods of high fertility regardless of how close the relationship is and one motivating women to become more interested in high-quality mates, an interest that becomes manifest in a desire to discuss relationship events with close (non-male-kin) associates, whether mothers or friends.

Another question raised by these data is whether females avoid contact with their fathers not because of the costs of inbreeding, but because they want to avoid paternal efforts to control their social and sexual behavior. Although we cannot completely rule out this possibility, the pattern of calls observed for mothers provides evidence against the avoidance of daughter guarding. Historically and cross-culturally, mothers (in addition to fathers) are guardians of daughters' sexuality, directly exerting control over daughters' sexual decisions (Fox, 1980; Goddard, 1987). If daughters were avoiding parental control during high-fertility days, then we should have found evidence of mother avoidance during periods of high fertility - but we did not. In addition, our findings are consistent with inbreeding avoidance patterns observed across mammalian species. Given the similar costs associated with inbreeding for women and for females of other species, it is likely that these cross-species patterns reflect systems for avoiding male kin during periods of high fertility. Of course, additional research is required to further test this claim.

To the extent that our data reflect the operation of inbreeding avoidance mechanisms, we expect the pattern we observed for parents to hold for siblings (brothers vs. sisters) and possibly for extended kin (e.g., uncles vs. aunts). This is because women should show heightened sensitivity to interactions that potentially jeopardize reproduction, especially during peak fertility. Furthermore, fertility-mediated avoidance should be observable using more direct behavioral measures, such as rates of face-to-face communication and dispersal patterns (e.g., distance traveled from home). Cell-phone records were a good index of association for our sample because subjects had limited face-to-face interactions with family during the school year; such records might not be as useful in contexts where women remain in close proximity to family.

In closing, this study calls attention to the intersection between kinship and sexual psychology, highlighting possible inbreeding avoidance behaviors in women. Despite the powerful connections documented in other mammals, kinship and its relation to sexual psychology has been a neglected area of research among humans (Daly, Salmon, \& Wilson, 1997). For instance, only recently have researchers started to investigate how people categorize other individuals according to genetic 
relatedness, an ability required for inbreeding avoidance (Lieberman, Tooby, \& Cosmides, 2007). There is also relatively little known about how different contexts affect the undesirability of genetic relatives as sexual partners (e.g., Haig, 1999) and how personal sexual aversions might translate into cultural sanctions such as incest taboos (e.g., Fessler \& Navarrete, 2004; Lieberman, Tooby, \& Cosmides, 2003, 2007). Moreover, whereas there has recently been much work on shifts in the qualities women desire in mates near the time of ovulation (e.g., Gangestad \& Thornhill, 2008; Pillsworth \& Haselton, 2006), this study suggests that there are corresponding shifts in psychological aversions designed to help women avoid reproductive costs when fertile. This potential pattern constitutes another promising area for future study. In general, we hope this study sparks additional lines of research that take into account the influence kinship has had on mate-choice systems as well as other facets of cognition and social behavior.

\section{Acknowledgments}

All authors contributed equally to this work. The authors would like to thank Christina Carvalho, Ashleigh Denny, Beth DiLeone, Kelly Gildersleeve, Nicole Graves, Jennifer Huang, Yelena Kashtuyeva, Kendra Leak, Christy Lopez, and Proud Usahacharoenporn for assistance conducting this research. We would also like to thank Leda Cosmides, Doug Kenrick, Mike McCullough, Steve Neuberg, and our two anonymous reviewers for their constructive comments on the manuscript.

\section{Declaration of Conflicting Interests}

The authors declared that they had no conflicts of interest with respect to their authorship or the publication of this article.

\section{Funding}

Funding for this study was provided by grants to Martie G. Haselton from the UCLA Council on Research and the UCLA Center for the Study of Women.

\section{References}

Baird, D., McConnaughey, D., Weinberg, C., Musey, P., Collins, D., Kesner, J., et al. (1995). Application of a method for estimating day of ovulation using urinary estrogen and progesterone metabolites. Epidemiology, 6, 547-550.

Bittles, A., \& Neel, J. (1994). The costs of human inbreeding and their implications for variation at the DNA level. Nature Genetics, 8, 117-121.

Boyd, S., \& Blaustein, A. (1985). Familiarity and inbreeding avoidance in the gray-tailed vole (Microtus canicaudus). Journal of Mammalogy, 66, 348-352.

Clutton-Brock, T. (1989). Female transfer and inbreeding avoidance in social mammals. Nature, 337, 70-72.

Daly, M., Salmon, C., \& Wilson, M.I. (1997). Kinship: The conceptual hole in psychological studies of social cognition and close relationships. In J.A. Simpson \& D. Kenrick (Eds.), Evolutionary social psychology (pp. 265-296). Mahwah, NJ: Erlbaum.
Fehring, R., Schneider, M., \& Raviele, K. (2006). Variability in the phases of the menstrual cycle. Journal of Obstetric Gynecological and Neonatal Nursing, 35, 376-384.

Fessler, D.M.T., \& Navarrete, C.D. (2003). Domain-specific variation in disgust sensitivity across the menstrual cycle. Evolution and Human Behavior, 24, 406-417.

Fessler, D.M.T., \& Navarrete, C.D. (2004). Third-party attitudes toward sibling incest: Evidence for Westermarck's hypotheses. Evolution and Human Behavior, 25, 277-294.

Fox, G. (1980). The mother-adolescent daughter relationship as a sexual socialization structure: A research review. Family Relations, 29, 21-28.

Gangestad, S.W., Simpson, J., Cousins, A., Garver-Apgar, C., \& Christensen, P. (2004). Women's preferences for male behavioral displays change across the menstrual cycle. Psychological Science, 15, 203-207.

Gangestad, S.W., \& Thornhill, R. (1998). Menstrual cycle variation in women's preference for the scent of symmetrical men. Proceedings of the Royal Society B: Biological Sciences, 265, 927-933.

Gangestad, S.W., \& Thornhill, R. (2008). Human oestrus. Proceedings of the Royal Society B: Biological Sciences, 275, 991-1000.

Goddard, V. (1987). Honour and shame: The control of women's sexuality and group identity in Naples. In P. Caplan (Ed.), The cultural construction of sexuality (pp. 166-192). New York, NY: Tavistock.

Haig, D. (1999). Asymmetric relations: Internal conflicts and the horror of incest. Evolution and Human Behavior, 20, 83-98.

Haselton, M., \& Gangestad, S. (2006). Conditional expression of women's desires and men's mate guarding across the ovulatory cycle. Hormones and Behavior, 49, 509-518.

Haselton, M.G., \& Gildersleeve, K.A. (in press). Can men detect ovulation? Current Directions in Psychological Science.

Ilmonen, P., Penn, D., Damjanovich, K., Clarke, J., Lamborn, D., Morrison, L., et al. (2008). Experimental infection magnifies inbreeding depression in house mice. Journal of Evolutionary Biology, 21, 834-841.

Ishida, Y., Yahara, T., Kasuya, E., \& Yamane, A. (2001). Female control of paternity during copulation: Inbreeding avoidance in feral cats. Behaviour, 138, 235-250.

Johnston, V., Hagel, R., Franklin, M., Fink, B., \& Grammer, K. (2001). Male facial attractiveness: Evidence for hormone-mediated adaptive design. Evolution and Human Behavior, 21, 251-267.

Lieberman, D., Tooby, J., \& Cosmides, L. (2003). Does morality have a biological basis? An empirical test of the factors governing moral sentiments relating to incest. Proceedings of the Royal Society B: Biological Sciences, 270, 819-826.

Lieberman, D., Tooby, J., \& Cosmides, L. (2007). The architecture of human kin detection. Nature, 445, 727-731.

Monard, A.-M., Duncan, P., \& Boy, V. (1996). The proximate mechanisms of natal dispersal in female horses. Behaviour, 133, 10951124.

Penton-Voak, I., Perrett, D., Castles, D., Burt, M., Koyabashi, T., \& Murray, L. (1999). Female preference for male faces changes cyclically. Nature, 399, 741-742. 
Pillsworth, E.G., \& Haselton, M.G. (2006). Women's sexual strategies: The evolution of long-term bonds and extra-pair sex. Annual Review of Sex Research, 17, 59-100.

Puts, D. (2005). Mating context and menstrual phase affect women's preferences for male voice pitch. Evolution and Human Behavior, 26, 388-397.

Rabe-Hesketh, S., \& Skrondal, A. (2008). Multilevel and longitudinal modeling using Stata (2nd ed.). College Station, TX: Stata Press.

Tooby, J. (1982). Pathogens, polymorphism, and the evolution of sex. Journal of Theoretical Biology, 97, 557-576.
Trivers, R.L. (1972). Parental investment and sexual selection. In M. Campbell (Ed.), Sexual selection and the descent of man (pp. 136-179). Chicago, IL: Aldine.

Wilcox, A.J., Dunson, D.B., Weinberg, C.R., Trussell, J., \& Baird, D.D. (2001). Likelihood of conception with a single act of intercourse: Providing benchmark rates for assessment of post-coital contraceptives. Contraception, 63, 211-215.

Winn, B., \& Vestal, B. (1986). Kin recognition and choice of males by wild female house mice (Mus musculus). Journal of Comparative Psychology, 100, 72-75. 